\title{
HOUSEHOLD-BASED LABOUR FORCE TRANSITIONS: A NEW DATABASE AND SOME METHODOLOGICAL CHALLENGES
}

\author{
Paul Callister \\ School of Government \\ Victoria University of Wellington \\ Susan G. Singley \\ Singley Associates
}

\begin{abstract}
This paper explores some methodological issues related to studying household labour force transitions and introduces a new dataset based on the Household Labour Force Survey (HLFS). To illustrate the complexity of the topic, we examine the following research question: How long do "work-poor" households remain "work-poor"? We endeavor to answer this question using the Household Transitions database, created for us by Statistics New Zealand. The database compiles eight quarters of data for several cohorts of HLFS households. Our analyses raise several methodological questions. While solving these problems is important if HLFS data are to be used in studying household based labour force transitions, these issues will also have to be confronted when analysing data from the Survey of Family. Income and Employment.
\end{abstract}

\section{Introduction}

Since at least the mid-1980s, employment has become less evenly distributed across New Zealand households a trend seen in a range of OECD countries (Singley and Callister 2002). There has been both a growth in households where all adults have a job (work rich) and those where no adult is employed (work poor). In parallel, in many industrialised countries there has been a polarisation of working hours in households (Callister 2004a). However, much of this national and international research has been cross sectional. Relatively little is known about how long households stay in a particular work state.

In terms of understanding social process, including those in the labour market, there is a growing appreciation in New Zealand of the strengths of longitudinal data. In part, this comes from seeing the value of overseas panel datasets, such as the Panel Survey of Income Dynamics in the United States, but also from the use overseas of linked labour force survey data (Morrison and Berezovsky 2001). Research that has emerged from New Zealand's two homegrown longitudinal studies, the Christchurch Child Development Study and the Dunedin Multidisciplinary Health and Development Study, is also proving to be very valuable. These studies have been running long enough to now start to provide some useful data on labour market transitions for individuals. In recognition of the value of panel data, in October 2002 Statistics New Zealand initiated the Survey of Family Income and Employment (SoFIE), the Ministry of Social Development is planning a longitudinal study of children, and Statistics New Zealand has set up the Linked Employer Employee Data project. Some relevant data from the first year of SoFIE are presented in this paper to help our understanding of the Household Labour Force Survey (HLFS) dataset that we introduce.

There are, however, other existing New Zealand datasets that can provide some longitudinal data. At the height of concerns about unemployment in New Zealand in the early 1990s, a number of papers presented at the Labour, Employment and Work conferences held during this period examined labour market transitions for individuals using a variety of official datasets. Grimmond (1993a) presented a paper using HLFS data on the dynamics of labour flows at the 1992 LEW conference, and this was a particularly popular topic in 1994 LEW conference with four papers presented using a number of data sources (Buckle and Peters 1993, Gardiner 1993, Irvine 1993, Silverstone and Gorbey 1993). There was one paper on this topic, using HLFS data, presented in 2000 (Morrison and Berezovsky 2001). In this same conference, Gobbi and Rea (2001) analysed unemployment spells using a new unemployment dataset based on administrative data collected by the New Zealand Employment Service. Yet, by 2002 , when unemployment had reduced considerably, the topic was not considered at the conference.

In this paper we introduce a new household-based dataset from the Household Labour Force Survey, created for us by Statistics New Zealand. The database compiles eight quarters of data for several cohorts of HLFS households. We then use this dataset to explore some methodological issues related to studying household based labour force transitions. To illustrate both the potential, but also complexity of the database, we examine two main research questions. The first is: How long do "work-poor" households remain "work-poor"? The second is: How do the characteristics of the long-term work poor households differ from those who would be identified using cross 
sectional data? Finally, in the paper we suggest some ideas for future research.

\section{Previous Research}

In New Zealand, a number of studies have examined the labour market transitions of individuals using HLFS data. The two earliest were by Grimmond (1993) and Woolf (1989). Along with papers presented at LEW conferences in the 1990s, Herzog (1996), Silverstone (1993) and Wood (1998) have also used this dataset to study labour market flows.

The early researchers focussed on a number of issues. A key one is the reliability of the data. For example, while in theory 87.5 percent of surveyed households should be matched between surveys, Silverstone and Gorbey (1995) note that the level of matching is closer to 75 percent, while Irvine (1993) found a matching rate of only 62.5 percent. A second problem is classification error, not unique to longitudinal datasets, but with the potential to create incorrect images of changes over time. Yet many of the researchers who have used linked data quote Woolf (1989) who suggests that, subject to some cautions with respect to measurement error, timing and weights, the HLFS transitions data is of reasonable quality.

The data for individuals have been used to explore a range of research questions. For example, Silverstone and Gorbey (1995) use these data to make the point that at any one time there are both job losses and job gains taking place, yet often only job losses are commented on in public debates. Irvine (1993) demonstrated that while risks of unemployment may be spread across the whole population, particular groups face long-term disadvantage. However, none of the New Zealand projects studied transitions in a household context. It is in the overseas literature that examples of household transitions can be found.

In the UK, Gregg and Wadsworth (1994) examined household-based labour force transitions using British LFS data that records the employment status for an individual a year before the survey date. The researchers argue that between the late 1970s and 1990 the probability of gaining employment fell dramatically for members of households with no one in paid work.

Their data show that in 197960 percent of non-employed houscholds had at least one earner a year later. But by 1993 this had declined to 25 percent. In contrast, they argue that the stock of two earner families was highly stable in all periods they studied.

Subsequent research in the UK also used data drawn from the Labour Forec Survey linking individuals within houscholds (Dorsett 2001). A dataset was constructed of over 18.000 non-employed working age couples spanning the period from the Spring of 1994 to the Summer of 2000. Specifically in relationship to studying work poor couples, Dorsett notes that in addition to the usual problem of attrition due to non-response to subsequent interviews, there are problems introduced by the complicated structure of the data. Specifically, couples only feature in his data while the partnership is intact and from the point of initially being observed as workless onwards. Hence, there are other reasons, apart from nonresponse, for not appearing in all waves.

Like many other studies, Dorsett showed strong evidence of similarities between partners with respect to a number of characteristics including: age; ethnicity; country of origin; qualifications; education; disability and health; type of worklessness; duration of unemployment; work experience; length of time since last job, and; whether the last job was manual or non-manual. For example, considering previous employment experience, while only 15 per cent of women in workless households had no experience of employment, the level was 63 per cent among those partnered with men who had never worked. He also considered couple formation and found that individuals who were employed were much more likely to acquire a working rather than a non-working partner. Furthermore, those who were unemployed were more likely to acquire unemployed rather than non-labour force (inactive) partners, while inactive people were more likely to acquire inactive partners.

When considering the characteristics of individuals in couples separately, Dorsett found that for men, nearly half of non-employment was explained by unemployment. For women, inactivity was much more prevalent. Family considerations were significant for women with more than half being inactive due to looking after the family or the home. Most male inactivity was accounted for by sickness or disability. Dorsett found that ill health and disability were important factors affecting more than half the sample and especially the men. Where health problems existed, they usually affected both the kind of work and the amount of work possible.

In terms of transitions, one fifth of workless couples had found work within a year, with the most common combination after this time being that of an employed man and an inactive woman. However, there were differences between those starting in a state of unemployment versus inactivity. For both sexes, inactivity was the most stable employment status with very few changes from one quarter to the next. Joint inactivity was similarly stable; nine out of ten such couples remained jointly inactive into the next time period. Movements between inactivity and work were rare. In fact, the only real evidence of such moves was among those men or women with working partners.

In relation to policy implications of his research, Dorsett argues that the high level of similarity between partners in a couple suggests problems of worklessness may be concentrated within a particularly hard-to-reach group of couple households. Policies that have been ineffective for one partner may be equally ineffective for the other partner. 


\section{Some Conceptual Problems in using Linked New Zealand HLFS Data}

Some of the problems in using HLFS data that link individuals within households have been highlighted in the outline of previous research. There is, however, a range of other issues to consider. Some simply relate to studying households rather than individuals, others relate to studying transitions over time.

First, there is the unit of analysis and any additional characteristics required for inclusion in the analysis. The unit of measurement we use is a household. It is not a family, although often the two will have a complete overlap. However, we also restrict our analysis to "working-age" households, which creates some methodological challenges. Our decision to focus on prime working age groups was based on earlier work in which we wanted to make our results compatible with international studies (Singley and Callister 2002) Classifying people within a particular age range is relatively straightforward for individuals. But where an age range is determined in relation to couples (and any other household members), when people fall outside that age range then the "statistical" household seems a little different from the real household. For example, a couple in which one partner was aged 64 and one was aged 68 , with one adult child living with them would fall into the "2-adult household, no dependent children" category. In the analysis, the 68 year old would be ignored.

Another example further illustrates potential problems. In the dataset children aged 15 and 16 are counted as dependent children if they are not employed, but counted as working-age adults if they are employed. So a single mother with an employed 15-year-old son would fall into the "2-adult household, no dependent children". While some behaviours might be similar to a married couple with no dependent children, such as some bargaining that may take place over hours of work, overall the two households are quite different.

A further challenge related to using households as the unit of analysis is the classification of ethnicity. In two or more adult households there is a significant chance that the adults will belong to different ethnic groups (Callister 2004b). In addition, ethnicity is fluid and there is the potential for some shifts in ethnic groups over time.

Studying households over time compounds many of these issues. For example, there is the issue of changes in household form over time. For example, single people may become part of a couple or couples may separate. However, early data from SoFIE (see Table 1), which shows transition over a period of a year, suggest that in most age categories these transitions are not that significant.

Table 1: Couple formation and couple separation over a period of one year, First data from SoFIE 2004

\begin{tabular}{lccc}
\hline & Partnered both \\
periods & $\begin{array}{c}\text { Non-partnered both } \\
\text { periods }\end{array}$ \\
\hline Male & $15-24$ & 87 & 96 \\
& $25-44$ & 97 & 85 \\
\multirow{4}{*}{ Female } & $45-64$ & 99 & 95 \\
& $15-24$ & 88 & 94 \\
& $25-44$ & 96 & 89 \\
& $45-64$ & 98 & 97 \\
\hline
\end{tabular}

Source: Statistics New Zealand

Another example has to do with classifying households according to the labour market status of household members and following changes over time. When labour market status is considered for individuals, there are many possible states, but generally three are considered: employed, unemployed and not in labour force. In using labour market data, most New Zealand researchers have focused on these three states. In their transitions study,
Morrison and Berezovsky (2001) label these: employed, jobless and not in the labour force. This provides a number of potential transitions between quarters for individuals (Table 2). In such a classification system, a simple analysis might be tracking those not in the labour force in the first quarter over the 8 quarters to see how many people do not exit this state. 
Table 2: Possible transitions for individuals across one quarter as used by Morrison and Berezovsky (2001)

\begin{tabular}{lllll}
\hline Quarter $_{t-1}$ & Quarter $_{t}$ & & & \\
\hline & $E_{1}$ & $J_{t}$ & $N_{1}$ & Total \\
$E_{t-1}$ & EE & EJ & EN & E. \\
$J_{t-1}$ & $\mathrm{JE}$ & $\mathrm{JJ}$ & $\mathrm{JN}$ & $\mathrm{J}$ \\
$\mathrm{N}_{t-1}$ & $\mathrm{NE}$ & $\mathrm{NJ}$ & $\mathrm{NN}$ & $\mathrm{N}$. \\
\hline
\end{tabular}

Dorsett (2001), in his United Kingdom (UK) study of labour force transitions for couples, initially begins with 25 possible labour market states for individuals. These include detailed breakdowns of being inactive such as: inactive, not wanting work, and a student or inactive, wanting work, but looking after family members. However, when studying transitions for both partners between quarters, in order to reduce complexity he reduces categories to 25 . However, this still produces very complex output and, just as importantly, means that the estimates from the data have to be treated with caution due to small sample sizes in each category. The advantage, however, is that his data do highlight major differences in behaviour depending on whether a person is seeking work or is inactive.
In our previous studies of polarisation of work, we collapsed employment status categories into two - these are either in employment, or not in employment. An individual in employment is considered to be "work rich" no matter what hours they work, while the unemployed and those not in the labour force are considered to be work poor. Reducing the number of potential categories reduces potential survey misclassification errors, but work status possibilities in each quarter nevertheless still become complex when two adult households, usually couples, are considered. Considering two adults requires bringing in a third category, that of mixed work (Table 3 ).

Table 3: Possible work-states for two adult households - Single point in time

\begin{tabular}{lllll}
\hline & & \multicolumn{2}{c}{ Adult 2 } & \\
\hline & Employed & Employed & Unemployed & Not in labour force \\
Adult 1 & Work rich & Mixed work & Mixed work \\
& Unemployed & Mixed work & Work poor & Work poor \\
& Not in labour force & Mixed work & Work poor & Work poor \\
\hline
\end{tabular}

A two adult household could start at one point in any of the three states and move into any of these states. However, as discussed, the household composition could also change, for example a couple raising children could become a sole parent household over one quarter. In addition, if the sample being tracked has some age restriction (such as looking at prime working age households) one, or both, individuals in that household could move out of this age range between quarters. This would exclude them from the sample being analysed (non-sample NS). An alternative, however, around age would be that two adult households needed to fit in a particular age range in the first quarter but this restriction could be relaxed in subsequent quarters.

When considering transitions for individuals, but also considering their household arrangement, such as sole parents and adults living on their own, the possible transitions are already relatively complex. Naturally, the potential transitions become more complex for two adult households, and this complexity expands the more adults are living in a household (Table 4).

Table 4: Possible transitions for two adult households (including couples) across one quarter

\begin{tabular}{llllll}
\hline Quarter $_{1-1}$ & Quarter, & & & & \\
& WR & MW & WP & NS & Total \\
$W_{t-1}$ & WR-WR & WR-MW & WR-WP & WR-NS & WR. \\
MW & MW-WR & MW-MW & MW-WP & MW-NS & MW \\
WP & WP-WR & WP-MW & WP-WP & WP-NS & WP \\
\hline
\end{tabular}

In the results section, we initially present some data across one quarter on the transition from all three possible work-statuses to all three statuses for two adult households. However, overall in the examples presented in this paper we focus primarily on transitions out of work poor status across all household types. In part, this 
is because focusing on all work-poor households rather than just two adult work-poor households increases the size of the sample and thus increases the reliability of the estimates.

\section{The Dataset}

In this study we use household-level data from the Household Labour Force Survey (HLFS). The HLFS covers approximately 15,000 households and 30,000 individuals from the civilian, non-institutionalised, usually resident population aged 15 years and over. A special HLFS database was created for us by Statistics New Zealand for this work. The dataset was derived from 10 complete rotation groups spanning the period beginning March 1999 to June 2001.
In the earlier part of the period that our database covers the HLFS was undergoing sample transition; this involved some rotation groups that were only in the survey for 4 quarters. Only rotation groups that were in for 8 quarters have been included in this dataset. The 10 groups were compiled into one dataset and information is available for each of 8 quarters, regardless of which calendar-date quarter each happens to represent. All households that were part these 10 rotation groups are included in the overall database. The following information is available for all households for all 8 quarters: family type, month and year of quarter, and household weight. In addition, information on the characteristics of individuals within the household is available on a quarterly basis for working-age households with 1 adult plus dependent child(ren), 2-adults, or 2 adults with dependent child(ren). The variables available for this subset of households are presented in Table 5.

Table 5: Variables available from special linked HLFS dataset for two-adult households (with and without dependent children) and for single-adult households with dependent children

\begin{tabular}{l}
\hline Individual characteristics (for person A and person B in two-adult households) \\
Ethnicity \\
Foreign born \\
Health limitation (for certain individuals) \\
Actual weekly hours of work \\
Usual weekly hours of work \\
Labour Force Stats \\
Main activity \\
Qualifications \\
Sex \\
Household characteristics \\
Number of dependent children \\
Age of youngest dependent child \\
Family Type \\
Household identifier \\
Household labour force status \\
Household type \\
Household weight \\
Number of non-working age adults in household \\
Number of those aged over 64 years in the households \\
Number of students in household
\end{tabular}

For our analysis presented in this paper, we focus on a subset of households with at least one working-age adult (aged 15-64) who is not a full-time student. Full-time students over the age of 16 were excluded from the analysis. Individuals aged 15 or 16 who are full-time students were counted as dependent children. Households were then classified into the following household type categories: One adult, One adult with dependent child(ren), Two adults, Two adults with dependent child(ren), Three adults, and Three adults with dependent child(ren). These households were then classified by labour force status of the working-age individuals. Households in which all working-age individuals were employed were classified as "work-rich"; those with no working-age adult in employment were classified as "work-poor"; and all others were classified as "mixed."
As already noted, in this paper our primary focus is on households where no adult is in paid work (which, while recognising Statistics New Zealand have a narrower technical definition of being jobless, we nevertheless, term "jobless"). In the period that our database covers, joblessness declined. In the March quarter of 1999 17.2\% of households were jobless, but this had reduced to $15.5 \%$ by March 2001. This was down from the peak of around 21 percent in 1992-1993.

\section{Results}

In this results section we are reporting mostly percentage information rather than numbers. This is due to weighting changes that take place each quarter therefore changing the base numbers. 
Table 6 illustrates transitions between quarters of two adult households that were work rich $(64.1 \%$ of these households), mixed work $(28.1 \%)$ or work poor $(7.8 \%)$ in the first quarter. It shows that most $(90.7 \%)$ of work-rich two-adult households stayed in that state when tracked over one quarter. This relative stability is in line with overseas studies. Mixed work households were not as stable, with $69.1 \%$ staying in that state between the two quarters. A slightly higher proportion of work-poor twoadult households $(76.2 \%)$ remained work poor between quarters. When moving out of work-poor status, the most likely state to move into was mixed work. That is, one adult moved into paid employment.

Table 6: Transitions in work-status for two adult households between quarters

\begin{tabular}{|c|c|c|c|c|c|}
\hline Quarter $_{t-1}$ & Quarter, & & & & \\
\hline & WR, & $\mathrm{MW}_{\text {, }}$ & WP, & $\mathrm{NS}_{\text {, }}$ & Total \\
\hline$W R_{1-1}$ & 90.7 & 8.1 & 1.2 & $\begin{array}{l}\text { Too small to } \\
\text { report }\end{array}$ & 100.0 \\
\hline$M W_{1-1}$ & 22.3 & 69.1 & 8.6 & $\begin{array}{l}\text { Too small to } \\
\text { report }\end{array}$ & 100.0 \\
\hline$W P_{1-1}$ & 6.4 & 17.4 & 76.2 & $\begin{array}{l}\text { Too small to } \\
\text { report }\end{array}$ & 100.0 \\
\hline
\end{tabular}

First quarter crosssectional data indicate that 16.4 percent of working age households were work poor, 22.1 percent mixed work and the majority, 61.5 percent, work-rich. Tables 7 and 8 show the transitions over eight quarters of all households that were recorded in the first quarter of the survey as being work-poor. The tables show the transitions out of being work poor in each quarter and the states households move into when ceasing to be work poor. For example, in the $2^{\text {nd }}$ quarter 80.5 percent of work poor households remained work poor, 8.5 percent moved into a mixed work status, while 11 percent became work rich by moving into paid work. The table ceases to follow any household that exits work poor status in any quarter. Some of these households may return to being work poor in subsequent quarters. For example, a household could be work poor in seven out of eight quarters, but in this exercise would only be recorded up to the quarter that they temporarily exited this status.

Table 7: Quarterly labour force transitions of the work poor for all households that were work-poor in the first quarter they were interviewed 1 st quarter to 4 th quarter

\begin{tabular}{|c|c|c|c|c|}
\hline & \multicolumn{4}{|c|}{ Percentage of work-poor in each work state in subsequent quarter } \\
\hline \multicolumn{5}{|l|}{ Ist Quarter } \\
\hline Work-rich & \multicolumn{4}{|l|}{61.5} \\
\hline Mixed & \multicolumn{4}{|l|}{22.1} \\
\hline \multirow[t]{10}{*}{ Work-poor } & 16.4-.>2nd Quarter & & & \\
\hline & Work-rich & \multicolumn{3}{|l|}{11.0} \\
\hline & Mixed & \multicolumn{3}{|l|}{8.5} \\
\hline & Work-poor & \multicolumn{3}{|l|}{$80.5-->3^{\text {rd }}$ Quarter } \\
\hline & & Work-rich & 8.7 & \\
\hline & & Mixed & 5.4 & \\
\hline & & \multirow[t]{4}{*}{ Work-poor } & 85.9-->4th Quarter & \\
\hline & & & Work-rich & 4.5 \\
\hline & & & Mixed & 5.6 \\
\hline & & & Work-poor & 89.9 \\
\hline
\end{tabular}


Table 8: Quarterly labour force transitions of the work poor for all households that were work-poor in the first quarter they were interviewed -4 th quarter to $8^{\text {th }}$ quarter

\begin{tabular}{|c|c|c|c|c|}
\hline \multicolumn{5}{|c|}{ Percentage of work-poor in each work state in subsequent quarter } \\
\hline \multicolumn{5}{|c|}{89.9 --> $>$ th Quarter } \\
\hline Work-rich & 4.0 & & & \\
\hline Mixed & 4.0 & & & \\
\hline \multirow[t]{10}{*}{ Work-poor } & 92.0-->6th Quarter & & & \\
\hline & Work-rich & 3.0 & & \\
\hline & Mixed & 3.5 & & \\
\hline & Work-poor & 93.5-->7th Quarter & & \\
\hline & & Work-rich & 3.9 & \\
\hline & & Mixed & 3.5 & \\
\hline & & Work-poor & 92.7-->8th Quarter & \\
\hline & & & Work-rich & 3.1 \\
\hline & & & Mixed & 1.7 \\
\hline & & & Work-poor & 95.2 \\
\hline
\end{tabular}

Tables 7 and 8 indicate that the proportion of households exiting work poor status declines over time. This can be seen more clearly in Figure 1 which shows what proportion of households that were work poor in the first quarter remained in this state over the full eight quarters. Just over 40 percent of work poor households remained in that state over the full eight quarters in the time period we studied. This would suggest that there is a group of workpoor households that exit relatively quickly from this state and a smaller group who remain in this state for a long period. Again, this is very much in line with the findings from overseas research. Of interest to both researchers and policy makers is how the characteristics of these two groups differ.

\section{Figure 1:}

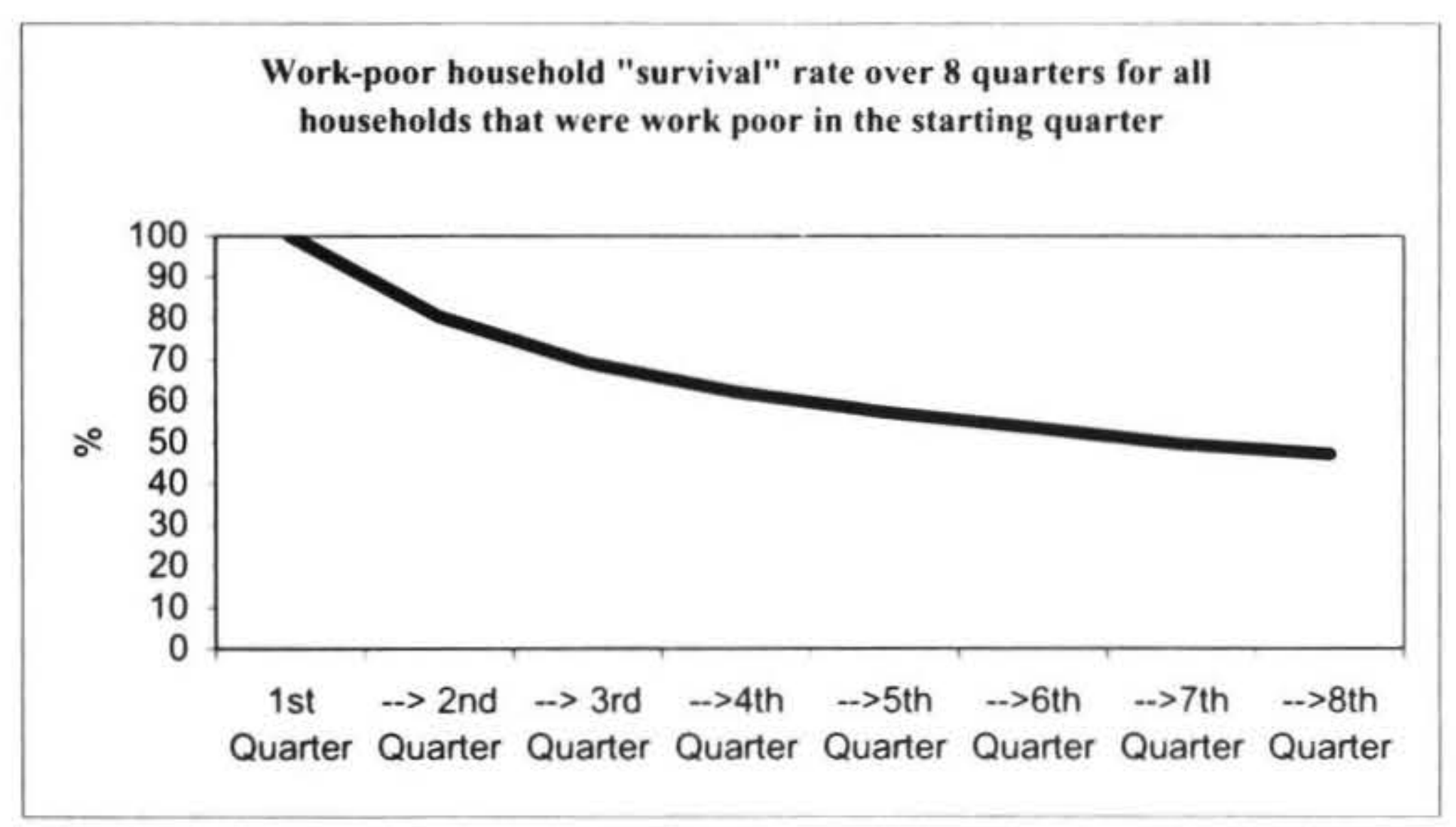

Tables 9, 10 and 11 identify selected characteristics of three groups of households. The first is the overall sample in the first quarter. This includes all working-age households regardless of the work status of the adults in them. The second are the characteristics of those households that were work poor in the first quarter. Finally, the characteristics of those households that were work poor over the whole eight quarters they were in the survey are shown. This allows an assessment of the characteristics that are associated with long-term employment disadvantage amongst households.
Column two of Table 9 confirms what we know from other cross sectional studies. That is, single adult households, with or without children, are more at risk of being work poor than two or multi-adult households. In the longer term (column three), it is the single adult households that stand out as being work poor. This is likely to include those "marginal" men who are separated from both work and family (Callister 2000). But it will also include older people who are not in work and, for whatever reason, are either choosing early retirement or cannot find a job. 
Table 9: Household form across whole sample, households that were work poor in the first quarter, and households that were work poor in all 8 quarters

\begin{tabular}{|c|c|c|c|}
\hline & \multicolumn{3}{|c|}{$\%$ of each household type } \\
\hline & $\begin{array}{c}\text { Whole dataset first } \\
\text { quarter }\end{array}$ & $\begin{array}{l}\text { First quarter work- } \\
\text { poor }\end{array}$ & $\begin{array}{c}\text { Work-poor all } 8 \\
\text { quarters }\end{array}$ \\
\hline I adult, no children & 21.2 & 41.2 & 60.2 \\
\hline $\begin{array}{l}\text { I adult, with } \\
\text { children }\end{array}$ & 9.0 & 29.5 & 20.8 \\
\hline $\begin{array}{l}\text { Two adults, no } \\
\text { children }\end{array}$ & 26.4 & 13.5 & 11.1 \\
\hline $\begin{array}{l}\text { Two adults, with } \\
\text { children }\end{array}$ & 28.5 & 12.5 & 6.3 \\
\hline $\begin{array}{l}\text { Three adults, no } \\
\text { children }\end{array}$ & 9.2 & 1.5 & 1.1 \\
\hline \multirow[t]{2}{*}{$\begin{array}{l}\text { Three adults, with } \\
\text { children }\end{array}$} & 5.7 & 1.9 & 0.5 \\
\hline & 100.0 & 100.0 & 100.0 \\
\hline
\end{tabular}

- some columns may not add to 100 due to rounding

Finally, Tables 10 and 11 provide a wider selection of characteristics of household members. However, they do not include all household types. Instead they cover the following family household types: Two adults, Two adults plus child(ren), One adult plus child(ren). Therefore, Tables 10 and 11 do not include one adult households with no children or multi-adult households.

Table 10: A selection of characteristics across whole sample and work-poor households

\begin{tabular}{|c|c|c|c|c|}
\hline & \multicolumn{4}{|c|}{$\%$ in each group for each variable } \\
\hline \multirow{3}{*}{ Age of person $\mathrm{A}$} & & $\begin{array}{l}\text { Whole dataset } \\
\text { first quarter }\end{array}$ & $\begin{array}{l}\text { First quarter } \\
\text { work-poor }\end{array}$ & Work-poor all 8 quarters \\
\hline & $15-24$ & 9.2 & 17.2 & 3.7 \\
\hline & $25-44$ & 59.0 & 53.3 & 49.6 \\
\hline \multirow{3}{*}{$\begin{array}{l}\text { Age of person } \\
\text { B* }^{*}\end{array}$} & $45+$ & 31.8 & 29.5 & 46.7 \\
\hline & $15-24$ & 10.8 & 20.9 & 6.7 \\
\hline & $25-44$ & 58.1 & 39.0 & 26.4 \\
\hline \multirow{2}{*}{$\begin{array}{l}\text { No. dependent } \\
\text { Children** }\end{array}$} & $45+$ & 31.2 & 40.1 & 66.9 \\
\hline & $1-2$ & 74.4 & 70.7 & 66.6 \\
\hline \multirow{3}{*}{$\begin{array}{l}\text { Age youngest } \\
\text { child** }\end{array}$} & $3+$ & 25.6 & 29.3 & 33.4 \\
\hline & $<6$ & 55.1 & 66.8 & 49.0 \\
\hline & $6+$ & 44.9 & 33.2 & 51.0 \\
\hline
\end{tabular}

* For two-adult households (with and without children)

** For households with children 
Table 11: A selection of characteristics across whole sample and work-poor households

\begin{tabular}{|c|c|c|c|c|}
\hline & & \multicolumn{3}{|c|}{$\%$ in each group for each variable } \\
\hline & & $\begin{array}{l}\text { Whole dataset } \\
\text { first quarter }\end{array}$ & $\begin{array}{c}\text { First quarter } \\
\text { work-poor }\end{array}$ & Work-poor all 8 quarters \\
\hline \multirow{4}{*}{$\begin{array}{l}\text { Ethnicity of } \\
\text { person A }\end{array}$} & Sole Maori & 8.7 & 23.6 & 20.8 \\
\hline & $\begin{array}{l}\text { Maori plus other } \\
\text { ethnicity }\end{array}$ & 2.8 & 5 & 7.1 \\
\hline & Other & 10.8 & 18.4 & 15.4 \\
\hline & Pakeha/Euro & 77.4 & 52.9 & 56.7 \\
\hline \multirow{4}{*}{$\begin{array}{l}\text { Ethnicity of } \\
\text { person } B^{*}\end{array}$} & Sole Maori & 6.7 & 18.2 & 15.8 \\
\hline & $\begin{array}{l}\text { Maori plus other } \\
\text { ethnicity }\end{array}$ & 2.5 & 3.9 & suppressed \\
\hline & Other & 11 & 19.7 & suppressed \\
\hline & Pakeha/Euro & 79.6 & 58 & 69.3 \\
\hline \multirow{2}{*}{$\begin{array}{l}\text { Foreign born } \\
\text { person A }\end{array}$} & Not FB & 79.9 & 78.2 & 76.1 \\
\hline & Foreign born & 20.1 & 21.9 & 23.9 \\
\hline \multirow{2}{*}{$\begin{array}{l}\text { Foreign born } \\
\text { person } \mathrm{B}^{*}\end{array}$} & Not FB & 80.9 & 74.1 & 67.9 \\
\hline & Foreign born & 19.1 & 25.9 & 32.1 \\
\hline
\end{tabular}

* For two-adult households (with and without children)

Statistics NZ suppresses weighted data with cell sizes less than 1000

In terms of the characteristics of the long-term work poor, Tables 10 and 11 suggest that:

- Older people are over-represented

- While Maori as a group are over-represented, this over-representation is stronger amongst those recording only Maori ethnicity

- When two adult households are considered, foreign born adults are more likely to be long term work poor

- While the differences are not strong, when households with children are focussed on it seems that larger families with older children may be more at risk of being long term workpoor

Many of these findings confirm what has already been found in cross sectional data, or data on transitions for individuals. Clearly, what would also be of interest would be the interaction between some of these variables. However, sample size quickly restricts the reliability of any multivariate analysis.

\section{Future Research}

The data presented in this paper are illustrative of how linked HLFS data could be used. The paper also indicates some challenges involved in their use. This was an experimental dataset created specially for us by Statistics New Zealand, and Statistics New Zealand retains ownership of these data. However, both the researchers and Statistics New Zealand would like to see more use made of these data. It seems such a dataset would be ideal for perhaps a Masters student to explore and, given that it has already been created, the additional costs in using these data would not be high. A range of research questions could be explored, including some relationships between changes in the labour market and changes in household form. In addition, more rigorous statistical analyses could be carried out to assess the relative importance of various "predictors" of households being long-term work-poor. It may be possible to explore the importance of other variables not examined here but included in the dataset, such as education level, health limitations, and presence of older $(65+)$ individuals within the household. Such analyses would help further assess the value and limitations of linked labour force data from the HLFS. While datasets such as SoFIE may ultimately provide a richer source of longitudinal data in many areas, based on our initial explorations linked HLFS household data appear to have the potential add a further and slightly different dimension that can assist us in understanding how the labour market operates.

\section{Acknowledgement}

We would like to thank the Foundation for Research, Science and Technology for funding this research. We would also like to thank Julie Woolf for her insightful comments on an early draft of the paper. 


\section{References}

Buckle, R. A. and Peters, J. M. (1995). Expectations and employment dynamics in New Zealand manufacturing, in P. S. Morrison (ed.), Labour, employment and work in New Zealand: Proceedings of the sixth conference, Wellington: Victoria University, pp. 76-86.

Callister, P. (2000). Living and working in New Zealand: Links between labour market change and household structure, Wellington: Institute of Policy Studies.

Callister, P. (2004a). Changes in working hours for couples, 1986 to 2001, paper presented at the eleventh Labour, employment and work in New Zealand conference, Wellington: Victoria University, November.

Callister, P. (2004b). Maori/non-Maori intermarriage, New Zealand Population Review, 29(2) 89-105.

Dorsett, R. (2001). Workless couples: Characteristics and labour market transitions, Policy Studies Institute, http://www.dwp.gov.uk/jad/2001/esr79 rep.pdf

Gardiner, P. (1995). An analysis of exit rates and duration dependence in registered unemployment, in P. S. Morrison (ed.), Labour, employment and work in New Zealand: Proceedings of the sixth conference, Wellington: Victoria University, pp. 67-75.

Gregg, P. and Wadsworth, J. (1994). More work in fewer households?, Discussion Paper No.72, National Institute of Economic and Social Research, United Kingdom.

Grimmond, D. (1993a). Unemployment duration: Evidence from the Household Labour Force Survey, in P. S. Morrison (ed.), Labour. employment and work in New Zealand: Proceedings of the fifth conference, Wellington: Victoria University, pp. 29-37.

Grimmond, D. (1993b). Labour force dynamics in New Zealand, NZIER Research Monograph 60, Wellington.
Gobbi, M. and Rea, D. (2001). Unemployment dynamics in New Zealand, in P. S. Morrison (ed.), Labour, employment and work in New Zealand: Proceedings of the ninth conference, Wellington: Victoria University, pp. 54-62.

Herzog, H. W. (1996). Job-loss and labour market outcomes under rapid structural adjustment: The case of New Zealand, Labour Market Bulletin, 1: $19-44$.

Irvine, S. (1995). The transition to employment: An analysis of gross flows from the Household Labour Force Survey, in P. S. Morrison (ed.), Labour, employment and work in New Zealand: Proceedings of the sixth conference, Wellington: Victoria University, pp. 56-66.

Morrison, P. S. and Berezovsky, O. (2001). Employment dynamics in regional labour markets: An application of gross flows analysis, in P. S. Morrison (ed.), Labour, employment and work in New Zealand: Proceedings of the ninth conference, Wellington: Victoria University, pp. 87-106.

Silverstone, B. (1993). Labour market flows in New Zealand, Waikato Regional Economic Bulletin, 2:9-13.

Silverstone, B. and Gorbey, S. (1995). Unemployment dynamics in New Zealand 1985-1994, in P. S. Morrison (ed.), Labour, employment and work in New Zealand: Proceedings of the sixth conference, Wellington: Victoria University, pp. 47-55.

Singley, S. G. and Callister, P. (2002). Trends in household employment inequality, in S. B. Blumenfeld (ed.), Labour, employment and work in New Zealand: Proceedings of the $10^{\text {th }}$ conference, Wellington: Victoria University, pp. 123-130.

Wood, J. S. (1998). Gross flows analysis of the New Zealand labour market, Unpublished Master of Social Science thesis, Waikato University.

Woolf, J. (1989). Gross flows estimates from the household labour force survey, Survey New Zealand Labour Force, 3: 32-42. 